\title{
Fingolimod Affects Transcription of Genes Encoding Enzymes of Ceramide Metabolism in Animal Model of Alzheimer's Disease
}

\author{
Henryk Jęśko ${ }^{1}$ • Przemysław L. Wencel ${ }^{2} \cdot$ Sylwia Wójtowicz $^{1}$ • Joanna Strosznajder ${ }^{1}$ • Walter J. Lukiw ${ }^{3,4,5}$. \\ Robert P. Strosznajder ${ }^{2}$
}

Received: 2 September 2019 / Accepted: 23 March 2020 / Published online: 30 April 2020

(C) The Author(s) 2020

\begin{abstract}
The imbalance in sphingolipid signaling may be critically linked to the upstream events in the neurodegenerative cascade of Alzheimer's disease (AD). We analyzed the influence of mutant (V717I) amyloid $\beta$ precursor protein (A $\beta P P)$ transgene on sphingolipid metabolism enzymes in mouse hippocampus. At 3 months of age $A \beta P P / A \beta$ presence upregulated enzymes of ceramide turnover on the salvage pathway: ceramide synthases (CERS2, CERS4, CERS6) and also ceramidase ACER3. At 6 months, only CERS6 was elevated, and no ceramide synthase was increased at 12 months. However, sphingomyelin synthases, which utilize ceramide on the sphingomyelinase pathway, were reduced (SGMS1 at 12 and SGMS2 at 6 months). mRNAs for sphingomyelin synthases SGMS1 and SGMS2 were also significantly downregulated in human AD hippocampus and neocortex when compared with age-matched controls. Our findings suggest early-phase deregulation of sphingolipid homeostasis in favor of ceramide signaling. Fingolimod (FTY720), a modulator of sphingosine-1-phosphate receptors countered the A $\beta$ PP-dependent upregulation of hippocampal ceramide synthase CERS2 at 3 months. Moreover, at 12 months, FTY720 increased enzymes of ceramide-sphingosine turnover: CERS4, ASAH1, and ACER3. We also observed influence of fingolimod on the expression of the sphingomyelinase pathway enzymes. FTY720 counteracted the A $\beta$ PP-linked reduction of sphingomyelin synthases SGMS1/2 (at 12 and 6 months, respectively) and led to elevation of sphingomyelinase SMPD2 (at 6 and 12 months). Therefore, our results demonstrate potentially beneficial, age-specific effects of fingolimod on transcription of sphingolipid metabolism enzymes in an animal model of AD.
\end{abstract}

Keywords Alzheimer's disease $\cdot$ Ceramide $\cdot$ Fingolimod $\cdot$ Sphingolipid $\cdot$ Sphingosine-1-phosphate $\cdot$ Sphingomyelin synthase

Henryk Ję́śo and Przemysław L. Wencel contributed equally to this work.

Robert P. Strosznajder rstrosznajder@imdik.pan.pl

1 Department of Cellular Signalling, Mossakowski Medical Research Centre, Polish Academy of Sciences, 5 Pawinskiego St., PL-02106 Warsaw, Poland

2 Laboratory of Preclinical Research and Environmental Agents, Mossakowski Medical Research Centre, Polish Academy of Sciences, 5 Pawinskiego St., PL-02106 Warsaw, Poland

3 LSU Neuroscience Center, Louisiana State University School of Medicine, New Orleans, LA, USA

4 Department of Neurology, Louisiana State University School of Medicine, New Orleans, LA, USA

5 Department of Ophthalmology, Louisiana State University School of Medicine, New Orleans, LA, USA

\section{Introduction}

Alzheimer's disease (AD) is the most widespread neurodegenerative disorder accounting for up to $70 \%$ of the estimated 47 million dementia cases present worldwide [1]. Extracellular senile plaques of amyloid $\beta(\mathrm{A} \beta)$ are a hallmark and a crucial element of AD neuropathology [2]. The V717I "London" mutation of $\mathrm{A} \beta$ precursor protein $(\mathrm{A} \beta \mathrm{PP})$ has been reported in familial (FAD)/early-onset $\mathrm{AD}$ [3]. The mutation increases $A \beta$ production and shifts the $A \beta P P$ metabolism in favor of the highly neurotoxic $A \beta_{42}$ isoform [4].

Aging of the central nervous system (CNS) creates vulnerable background for the development of the disease and alters numerous signaling and metabolic pathways linked to neuronal phenotype, function, and survival/death. Both aging and $\mathrm{AD}$ are accompanied by alterations in the metabolism of bioactive sphingolipids, a precisely regulated network of compounds (Fig. 1) with strong pro- or anti-apoptotic activities [5-8]. The pro-apoptotic sphingolipid ceramide is synthesized 


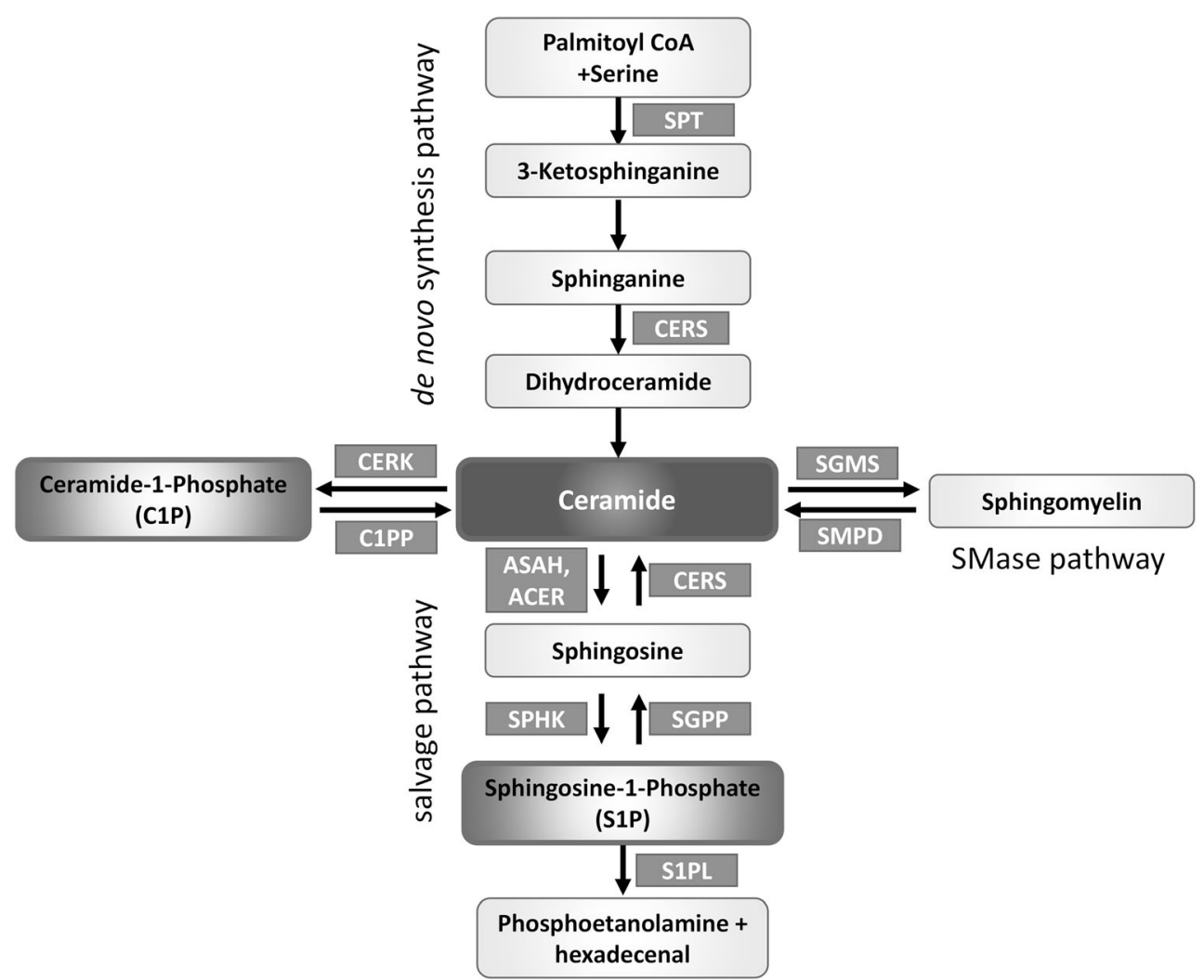

Fig. 1 Ceramide biosynthesis pathways. Ceramide (Cer) can be produced on each of the three marked pathways. Serine palmitoyltransferase (SPT) catalyzes the first step in the de novo pathway and controls the rate of ceramide biosynthesis. Ceramide synthases (CERS) take part both in the salvage and de novo pathways, using different substrates (sphingosine and sphinganine). Metabolic shuttling between ceramide and sphingomyelin is done by sphingomyelin synthase- $-\mathrm{S}(\mathrm{G}) \mathrm{MS}$, and sphingomyelin phosphodiesterase (SMPD). Sphingosine is produced from ceramide by ceramidases (ASAH, ACER). Sphingosine can be

on several distinct metabolic pathways and can be converted by ceramidases into sphingosine [9]. A single phosphorylation reaction turns each of them into molecules that typically exert strong pro-survival influence (C1P, ceramide-1-phosphate, and S1P, sphingosine-1-phosphate). S1P modulates cell survival, and also proliferation, differentiation, morphology, neurotransmission, and synaptic plasticity. In addition to its second messenger role, S1P can signal via cell membrane receptors (S1PR1 to S1PR5) that bind $\mathrm{G}_{12 / 13}, \mathrm{G}_{\mathrm{q}}$, and $\mathrm{G}_{\mathrm{i}}$ proteins [9]. The PI3K-Akt pathway responds to $\mathrm{G}$ proteins and modulates transcription factors (TFs) including AP-1 (activator protein-1, which is in turn one of crucial regulators of sphingolipid metabolism enzymes including SPHK1, CERS4, and CERS5 [10, 11]), or NF-kB (nuclear factor $\mathrm{\kappa B}$, a pleiotropic sensor of stress and metabolic signals engaged in survival/death decisions and immune activation [12]). The contrasting roles of closely related sphingolipids require precise regulation, as reflected in the term sphingolipid rheostat.

$\mathrm{A} \beta$ has been shown to alter the expression of genes engaged in sphingolipid signaling [13]. The effect seems to have phosphorylated by the sphingosine kinases (SPHK1 and SPHK2) to form sphingosine-1-phosphate (S1P), while the ceramide kinase CERK phosphorylates ceramide to ceramide-1-phosphate (C1P); both phosphates have signaling activities approximately opposite to those of sphingosine and ceramide. Dephosphorylation of S1P and C1P is carried out by their respective phosphatases, SGPP and C1PP. The highly controlled enzymatic conversion that yields compounds of radically different activities in a single reaction is reflected in the idea of the sphingolipid rheostat

profound significance in actual $\mathrm{AD}$ cases, where early, widespread disturbances in the ceramide-linked metabolic pathways correlate with the disease progression. Ceramide may act as a pro-apoptotic molecule, and-together with deregulated $\mathrm{S} 1 \mathrm{P}$ - can also alter stress signaling, A $\beta \mathrm{PP}$ processing, or tau phosphorylation [14]. Ceramide and S1P are engaged in structural aspects of biological membranes, neuronal axons, and synapses (lipid rafts, protein anchoring), and in mitochondrial maintenance [15-20]. Their interactions with the PI3K-Akt and NF-kB pathways allow cross-talk with metabolic control/nutrient sensing [14]. Human AD brain samples display high mRNA levels of CERS1 and CERS2 (ceramide synthases), SPTLC2 (serine palmitoyltransferase), or SGPL1 (S1P lyase), and low expression of CERK (ceramide kinase) or ASAH1 (acid ceramidase) [8]. These changes result in increased concentrations of some ceramide species and reduced S1P, potentially resulting in a pro-apoptotic shift in the signaling equilibrium $[6,8]$. Moreover, elevated ceramides may alter $\mathrm{A} \beta \mathrm{PP}$ maturation and its cleavage by secretases, closing the circle of self-fueling pathology [21-23]. Sphingolipid 
alterations occur very early during disease development, suggesting close links with upstream events of $\mathrm{AD}$ pathogenesis [6-8]; moreover, altered sphingolipid content in the cerebrospinal fluid (CSF)/blood may be a useful marker [24, 25].

Although experimental AD models are being criticized for recreating only selected aspects of the disease with varying fidelity [26], they may be highly useful in the elucidation of molecular/biochemical events mediating the neurotoxicity of $\mathrm{A} \beta$ [27]. $\mathrm{A} \beta$ peptides modulate the enzymes of sphingolipid metabolism and S1P receptors in cellular models; thus, $A \beta$ 's effect appears to be relatively direct [13]. We have recently demonstrated the influence of neuronal expression of V717I $\mathrm{A} \beta \mathrm{PP}$ on the mRNA levels of sphingosine kinases and cell surface S1P receptors [27].

Unfortunately, up until now, no therapeutic strategy exists that would protect neuronal cells against degeneration and death in AD. Many types of drugs were developed de novo but without success [26, 28]. Repurposing of already developed and approved compounds is an innovative approach that avoids part of the enormous workload and time required [29]. Fingolimod (FTY720, Gilenya ${ }^{\mathrm{TM}}$ ) is a clinically available compound approved by the U.S. Food and Drug Administration and European Medicines Agency for the treatment of relapsing remitting multiple sclerosis (MS). FTY720 can be administered in multiple ways (orally for the therapy of MS) and crosses the blood-brain barrier [30]. FTY720 is a sphingosine analogue; its phosphorylation by sphingosine kinases (SphKs) changes it into an analogue of S1P, capable of binding the cell surface S1P receptors. The mechanism of action employed in its current therapeutic application comprises of activation-induced feedback internalization of cell surface S1P receptors, and the resulting inhibition of S1P signaling in immune cells. Binding of S1P or FTY720P (phosphorylated, active form of fingolimod) to S1PRs activates the PI3K-Akt pathway, whose disruption in $\mathrm{AD}$ [31] may be one of pathomechanisms of neurodegeneration $[32,33]$. Through PI3K-Akt, S1P receptors can inhibit GSK-3 $\beta$, a tau kinase [34]. S1PRs also modulate p38, ERK, Jnk, and the TNF receptor-associated factor TRAF2. Through modulation of cellular signaling, S1P and S1PRs target nuclear transcription factors, including AP-1, NF-kB, or FOXO3a [17, 31, 35, 36], which influence pathways important for stress and immune response [10, 11, 36, 37], and also ensure feedback regulation of selected sphingolipid metabolism enzymes and S1P receptors. The S1PR-sensitive changes in gene expression might also alter axonal connectivity [38] and the availability of neurotrophic factors [39]. Therefore, at least majority of these TFs should be available for pharmaceutical modulation with fingolimod, enabling modulation of critical aspects of the neurodegenerative process. S1P and FTY720P inhibit class I histone deacetylases (HDACs) [40-42]. Interaction with HDACs may have direct consequences in neurodegenerative and related conditions through modification of activated microglia phenotypes [43, 44]. FTY720 shows protective activity in demyelination and blood-brain barrier (BBB) damage [44-46]. Moreover, fingolimod has also been suggested to exhibit (possibly selective) antibacterial properties, which might contribute to its efficiency in BBB and neuronal protection [47]. Following the known fact of intestinal dysfunction in $\mathrm{PD}$, the potential role of gut microbiota alterations (dysbiosis) and the influence of FTY720 have also been analyzed in the disease [48]. Finally, FTY720 enhances learning/ memory while reduction of S1P levels impairs memory through high HDAC activity and altered gene expression profile [41]. Therefore, FTY720 constitutes an attractive potential drug candidate, although its complex influence upon neuronal phenotype and survival must be characterized in depth to ensure any successful therapeutic usage in neurodegenerative disorders.

The aim of the study was to analyze the effect of the administration of the potentially neuroprotective, clinically available drug FTY720 on the $A \beta P P$ (V717I)-induced changes in the expression of genes coding enzymes engaged in ceramide metabolism in the hippocampus of 3-, 6-, and 12month old mice.

\section{Materials and Methods}

\section{Animals}

Female FVB-Tg(Thy1; APP LD2/B6) mice express human A $\beta$ PP harboring the "London" V717I mutation under control of thyl promoter fragment which displays specificity towards neurons of the brain and spinal cord $[27,49,50]$. The model successfully recreates a relatively broad spectrum of behavioral, electrophysiological, and biochemical features of $\mathrm{AD}$ [49, 50]. The mice start displaying first behavioral abnormalities up to 8 weeks of age [49]. Starting from the age of approximately 3 months, the animals gradually develop agitation; cognitive disturbances appear at 3 to 6 months. These changes are accompanied by altered reactivity to neurotransmitters (observed at 3-4 months of age) and electrophysiological alterations (at between 5 and 7 months) [49]. Sizeable cortical and hippocampal $\mathrm{A} \beta$ histopathology was observed starting from the age of 13 months $[49,50]$.

The A $\beta$ PP-expressing animals were used at the age of 3,6 , or 12 months to compare gene expression patterns with controls, which did not inherit the transgene. Animals were treated intraperitoneally, daily for 2 weeks (15 injections) with $1 \mathrm{mg} / \mathrm{kg}$ b.w. FTY720 in $0.9 \% \mathrm{NaCl}$ (or $\mathrm{NaCl}$ only for control treatment), as described previously [27]. The dose and duration chosen were based on analysis of literature data [51-53] and were identical as used in our previous work where we observed an array of relatively mild changes in response to the treatment [27]. One day after the last dose, the mice were 
decapitated and their brains isolated on ice, dissected, and flash-frozen in liquid nitrogen.

The Animal House of the Mossakowski Medical Research Centre PAS, Warsaw, Poland, bred the mice under specific pathogen-free (SPF) conditions in controlled temperature/ humidity conditions, 12-h light/dark cycle. Every effort was made to minimize the number of animals and to reduce the amount of pain, distress, and/or discomfort. All experiments were approved by the IV Local Ethics Committee for Animal Experimentation in Warsaw and performed in accordance with guidelines of the EU Directive 2010/63/EU and with the ARRIVE guidelines.

\section{Real-time Polymerase Chain Reaction Measurement of Gene Expression}

The measurements were performed as described previously [27]. Briefly, nucleic acids were extracted using the Chomczynski method with TRI reagent (Sigma-Aldrich/ Merck), DNA digested with DNase I (Sigma-Aldrich), and the concentration and purity of obtained RNA assessed spectrophotometrically $\left(\mathrm{A}_{260} / \mathrm{A}_{280}\right)$. Total RNA reverse transcription was performed with AMV (avian myeloblastosis virus) reverse transcriptase and random primers (Applied Biosystems, Foster City, CA, USA). Real-time PCR was done using TaqMan Gene Expression Assays on Applied Biosystems 7500 Real-Time PCR System. The following genes were analyzed: ACER2 (Mm00519876_m1), ACER3 (Mm00502940_m1), ASAH1 (Mm00480021_m1), CERS2 (Mm01258345_g1), CERS4 (Mm00482658_m1), CERS6 (Mm00556165_m1), SGMS1 (Mm00522643_m1), SGMS2 (Mm00512327_m1), SMPD2 (Mm01188195_g1), SPTLC1 (Mm00447343 m1), and SPTLC2 (Mm00448871_m1). Gene expression was calculated using the ddCt method and normalized against actin beta (ACTB, Mm00607939_s1).

\section{Statistical Analysis}

mRNA expression levels are expressed as $\mathrm{Rq}$ (relative quantity). Each value is a mean \pm SEM of three to five samples in tri- to quadruplicate ( $n=3$ to 5). ANOVA (two-way analysis of variance) with Tukey post hoc test was used for multiple comparisons. Statistical significance was accepted at $p<0.05$. The analysis was performed using GraphPad Prism package (GraphPad Software, San Diego, CA).

\section{Control and AD Brain Tissue Analysis}

Human brain samples were selected from archived tissues or extracts at the Louisiana State University Neuroscience Center, New Orleans, LA, from the University of California at Irvine CA, USA, and from the Oregon Health Sciences Center, Portland, OR, USA; archived RNA samples were also obtained from the University of Toronto (Toronto, Canada). All RNAs were isolated from sporadic AD and control hippocampal and superior temporal lobe neocortical tissue samples having a mean post-mortem interval (PMI; death to brainfreezing interval) of $4.2 \mathrm{~h}$ or less as PMI is a factor that can affect RNA quality [54-56]. "Center to establish a registry for Alzheimer's disease-National Institutes of Health" (CERAD$\mathrm{NIH})$ criteria were used to categorize AD tissues in accordance with established guidelines; AD tissues used had a clinical dementia rating (CDR; an index of cognitive decline) ranging from 1 to 3 , indicating mild to a severe stage [55, 56]. Brain tissues were used in accordance with the institutional review board/ethical guidelines at the Louisiana State University Health Sciences Center and donor institutions [54-56].

\section{Microarray-Based Analysis of Gene Expression Using DNA Arrays}

Total RNA was isolated from control and AD-affected human brain neocortex and hippocampus using TRIzol (Invitrogen) as previously described [54-59]; RNA quality was assessed using an Agilent Bioanalyzer 2100 (Lucent Technologies/ Caliper Technologies; Palo Alto, CA, USA) and RNA integrity number (RIN) values were typically 8.0-9.0 indicating high-quality total RNA [60-62]. Control and AD brain RNA samples were labelled, hybridized, and analyzed using 27,000 mRNA target GeneChips (Affymetrix, Palo Alto, CA, USA) as previously described [54, 55, 60-62].

\section{Results}

The expression of the disease-related (V717I) variant of human $A \beta P P$ has exerted an age-specific effect on numerous genes linked to ceramide metabolism in the hippocampus. Strikingly, we observed most changes in the youngest age group. The expression of serine palmitoyltransferase (SPTLC), the rate-limiting enzyme of the de novo ceramide synthesis did not change in the hippocampus of 3,6 , or 12 months old animals in response to A $\beta$ PP expression (data not shown). Alterations in the activity of the genes coding other enzymes of ceramide metabolism may have important influence on the delicate signaling equilibrium. In the hippocampus of 3-month-old transgenic mice $\left(\mathrm{APP}^{+}\right)$, ceramide synthases CERS2, CERS4, and CERS6 (which take part both in the de novo and salvage pathways) were significantly upregulated as compared with control animals (Fig. 2). However, the effect gradually disappeared at later ages. Among ceramide synthases, only CERS6 was elevated at 6 months, while no CERS gene expression was altered by A $\beta P P$ at 12 months (Fig. 2). 
Hippocampus 3months
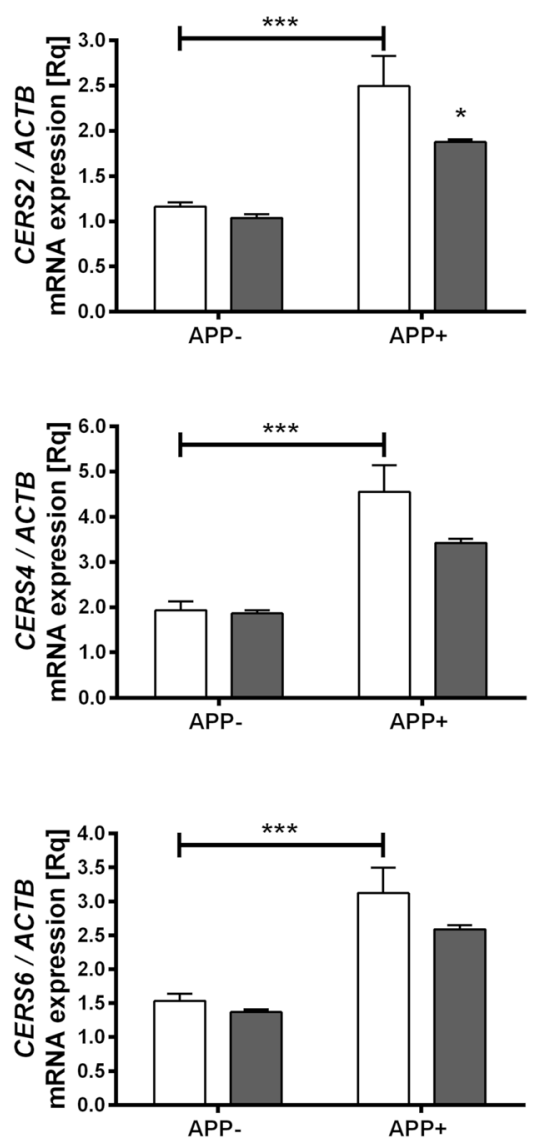

Fig. 2 The effect of fingolimod (FTY720) on mRNA expression of ceramide synthases in the hippocampus of $A \beta P P$ (V717I)-transgenic mouse. mRNA expression of CERS2, CERS4, and CERS6 was measured with real-time PCR in the hippocampus of $A \beta P P$-transgenic and control mice at the age of 3,6 , and 12 months. $* p<0.05 ; * *<0.01$;

Ceramidases convert ceramide further into sphingosine on the salvage pathway; sphingosine is considered as a proapoptotic compound, and may also serve as a precursor for the strongly anti-apoptotic S1P. We observed higher mRNA for ACER3 in 3-month-old hippocampus of $\mathrm{APP}^{+}$mice as compared with $\mathrm{APP}^{-}$animals (Fig. 3). Together with the above-mentioned changes in ceramide synthases, it suggests not only intensified ceramide generation but also its utilization, leading to accelerated metabolic turnover between ceramide and sphingosine. However, no changes in ceramidases were observed at 6 or 12 months of age (Fig. 3).

Ceramide is also utilized on the sphingomyelinase pathway by sphingomyelin synthases (SGMS). Significant reduction was observed in $\mathrm{APP}^{+}$hippocampus at 6 months (SGMS2) and 12 months (SGMS1), as shown in Fig. 4. The differences in subcellular localization and some functions of the two sphingomyelin synthases $[63,64]$ might affect the outcome
Hippocampus 12months
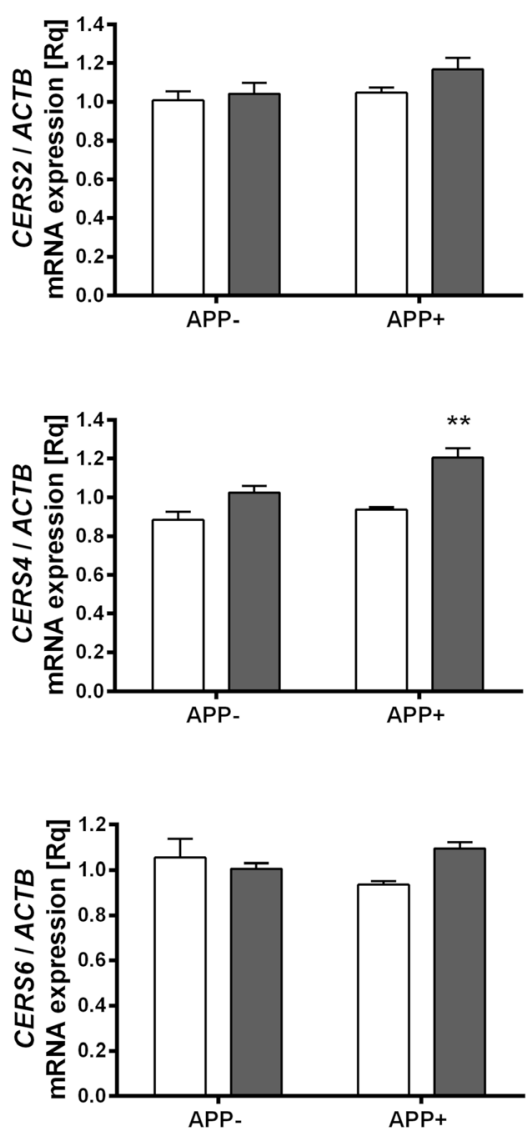

$* * * p<0.001$ as compared with the corresponding controls (horizontal bar: $\mathrm{APP}^{-}$mock-treated with $\mathrm{NaCl}$ vs. $\mathrm{NaCl}$-administered $\mathrm{APP}^{+}$mice; stars with no horizontal bar mean significant difference between $\mathrm{NaCl}$ and FTY720-treated animals within each group)-ANOVA with Tukey post hoc test

of their age-specific regulation. The sphingomyelinase SMPD2, which catalyzes the opposite reaction, did not change significantly at any age, thus suggesting a shift from sphingomyelin towards ceramide (Fig. 5).

Fingolimod (FTY720) notably countered the A $\beta$ PPinduced elevation of CERS2 expression in 3-month-old $\mathrm{APP}^{+}$hippocampus. At 6 months of age, no effect of FTY720 on ceramide synthases was observed. At 12 months, FTY720 only upregulated CERS4, which was unaffected by A $\beta$ PP transgene (Fig. 2). Similarly, fingolimod also had agedependent influence on the hippocampal expression of ceramidases, which remained unchanged by A $\beta P P$ : it significantly increased $A S A H 1$ at 6 months and $A C E R 3$ and $A S A H 1$ at 12 months (Fig. 3). Fingolimod also countered the $A \beta /$ A $\beta$ PP-related drop of sphingomyelin synthases: SGMS2 at 6-month-old and SGMS1 at 12-month-old hippocampus (Fig. 4). However, FTY720 also increased the expression of 

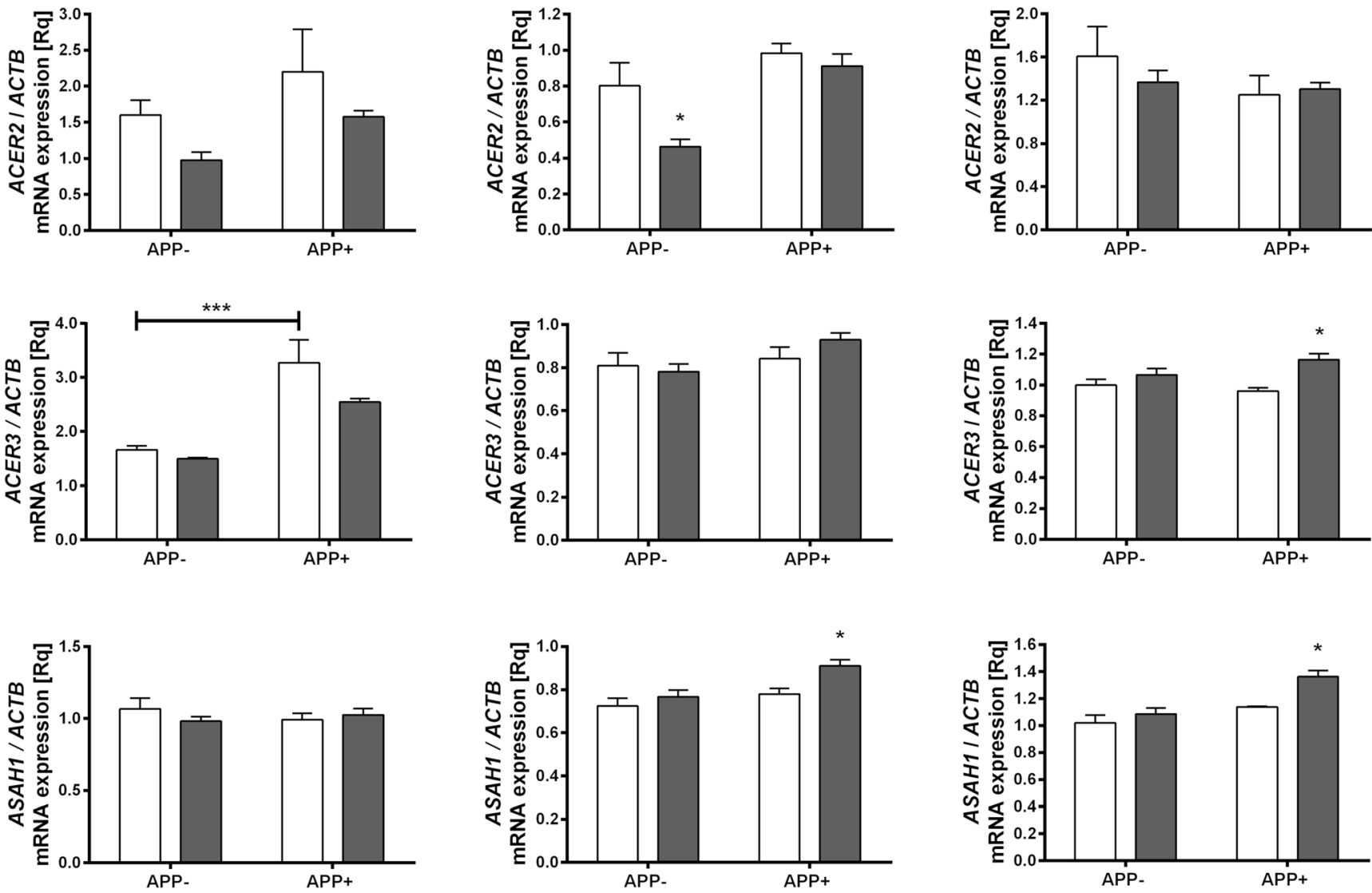

Fig. 3 The influence of fingolimod on the gene expression of ceramidases in the hippocampus of $A \beta P P$ (V717I)-transgenic mouse. mRNA expression of $A C E R 2, A C E R 3$, and $A S A H 1$ was measured with real-time PCR in the hippocampus of $A \beta P P$-transgenic and control mice

at the age of 3, 6, and 12 months. $* p<0.05 ; * * * p<0.001$ as compared with the corresponding controls (horizontal bar: $\mathrm{APP}^{-}$vs. $\mathrm{APP}^{+}$; stars without the bar: the effect of FTY720 treatment within each group)ANOVA with Tukey post hoc test

SMPD2, which was unchanged by A $\beta$ PP (at 6 and 12 months-Fig. 5).

Control- and age-matched human neocortex and hippocampus samples were also analyzed for mRNA abundance for the sphingomyelin synthases SGMS1 and SGMS2. Both $S G M S 1$ and SGMS2 were observed to be downregulated in both $\mathrm{AD}$ neocortex and hippocampus when compared with age-matched controls (Fig. 6). The levels of mRNA for CERS, ACER, ASAH, and SMPD were not significantly altered between control and AD samples (data not shown).

\section{Discussion}

Evidence is accumulating for the engagement of sphingolipid signaling in the pathogenesis of AD. The alterations that favor ceramide signaling over S1P occur very early in the disease development and correlate with its severity $[6,8]$. Ceramide generation is enhanced during what has been proposed as pre-
MCI (pre-mild cognitive impairment), and diminishes at late disease stages [7]. The AD-linked changes appear to be an escalation of trends observed in healthy aging [5], suggesting that sphingolipids might be a part of the mechanisms that link $\mathrm{AD}$ with advanced age. The sources of the age-/AD-related disturbances in the metabolism of bioactive sphingolipids are not fully understood. The ability of cell surface S1P receptors to regulate gene expression via $\mathrm{AP}-1$ and $\mathrm{NF}-\mathrm{KB}$ is a very important aspect both due to its potential significance for the disease mechanism, and to its usefulness as a research (and potentially therapeutic) tool.

The murine A $\beta P P$ (V717I)-transfected model has been shown to largely replicate an array of $\mathrm{AD}$ features in a characteristic time sequence $[49,50]$ (see "Materials and Methods"), including numerous changes in sphingolipid metabolism/signaling observed in the diseased brain [27]. Together with the results from cellular models [13], it suggests that the observed disturbances in sphingolipids might stem in a relatively direct way from the influence of $A \beta$, further 

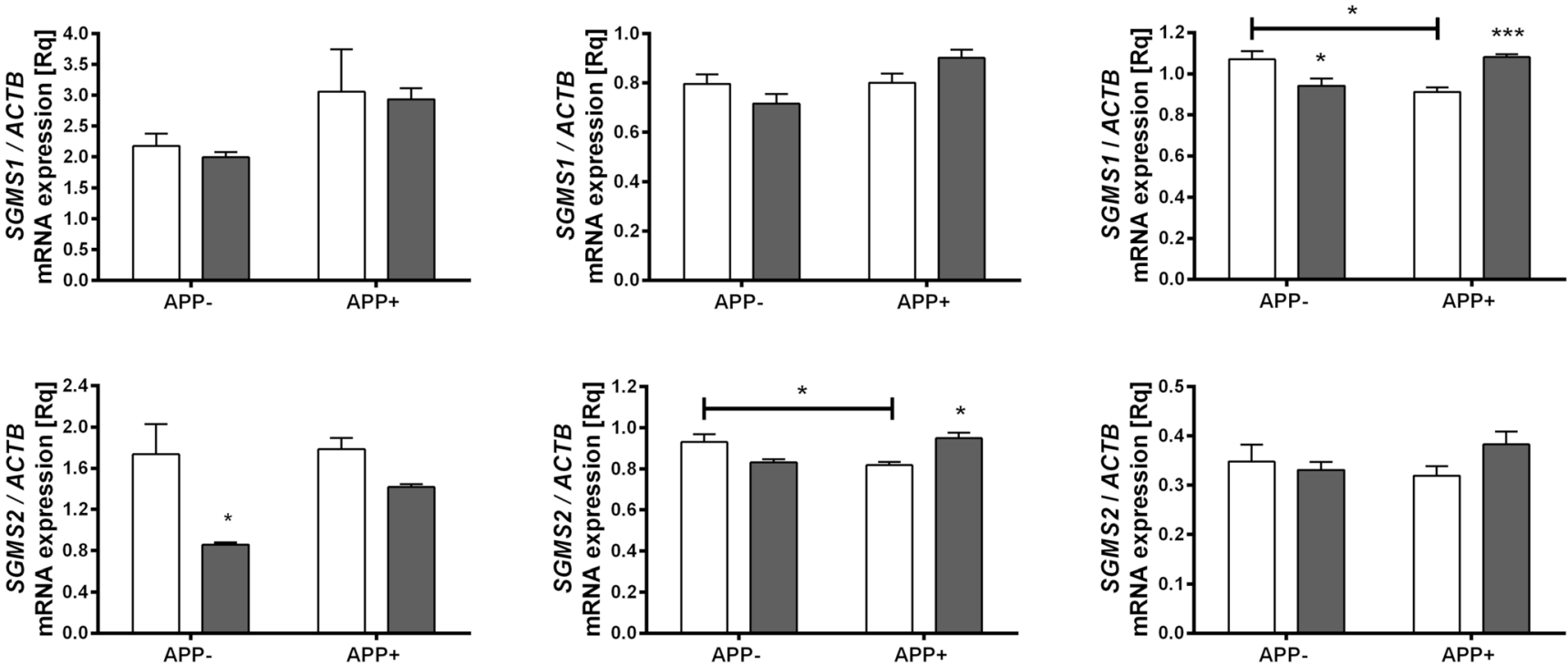

Fig. 4 Fingolimod-induced changes in the gene expression of sphingomyelin synthases in the hippocampus of $A \beta P P$ (V717I)transgenic mouse. mRNA expression of SGMS1 and SGMS2 was measured with real-time PCR in the hippocampus of $A \beta P P$-transgenic

and control mice at the age of 3,6 , and 12 months. $* p<0.05$; $* * * p<0.001$ as compared with the corresponding controls (horizontal bar: $\mathrm{APP}^{-}$vs. $\mathrm{APP}^{+}$; stars without the bar: the effect of FTY720 treatment within each group)-ANOVA with Tukey post hoc test

stressing the possible critical role of sphingolipids in the core mechanisms of $A \beta$ neurotoxicity. In our previous study, we observed age- and A $\beta P P$ (V717I)-related reduction of $S P H K 2, C E R K$, and SIPRs mRNAs, which largely mirrored the changes observed in human hippocampal post-mortem AD material (lower SPHK1 and SPHK2, S1PR1, and $C E R K)$ [27]. The reduction of sphingosine kinase expression should have negative impact upon cellular survival, and indeed, BCL2 levels were reduced [27].

While the sphingolipid rheostat model originally ascribed clearly distinct pro- or anti-apoptotic roles to respectively ceramide and S1P/C1P [9], newer data suggest a more complex picture $[65,66]$. However, our previous results on the age- related reduction of $B C L 2$ expression in $\mathrm{A} \beta \mathrm{PP}$-transgenic mice seem to confirm that in the case of $A \beta$ neurotoxicity there is a shift towards elevated pro-apoptotic signaling at the expense of the survival signals [27]. It is also likely that changes in the multiple signaling and neurotransmitter pathways that interact with sphingolipids [14] impact neuronal phenotype (synaptic maintenance and function, regulation of mitochondrial hemeostasis, stress response). In the current work, we have noted that in the absence of changes in the rate-limiting serine palmitoyltransferase, upregulation of three ceramide synthases in the 3-month-old hippocampus (elevated CERS6 persisted into the age of 6 months), together with one of the ceramidases (ACER3), may alter the metabolic turnover of ceramide.
Hippocampus 3months

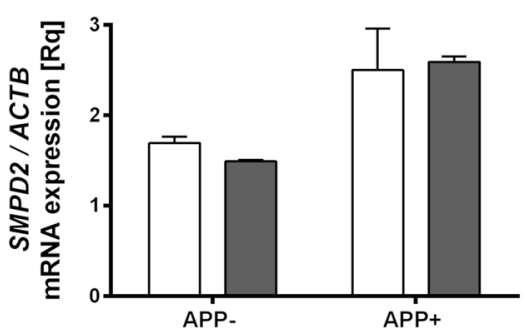

Fig. 5 The influence of fingolimod on mRNA expression of sphingomyelinase in the hippocampus of $A \beta P P$ (V717I)-transgenic mouse. mRNA expression of SMPD2 was measured with real-time
Hippocampus 6months

$\square \mathrm{NaCl}$ FTY720 in $\mathrm{NaCl}$
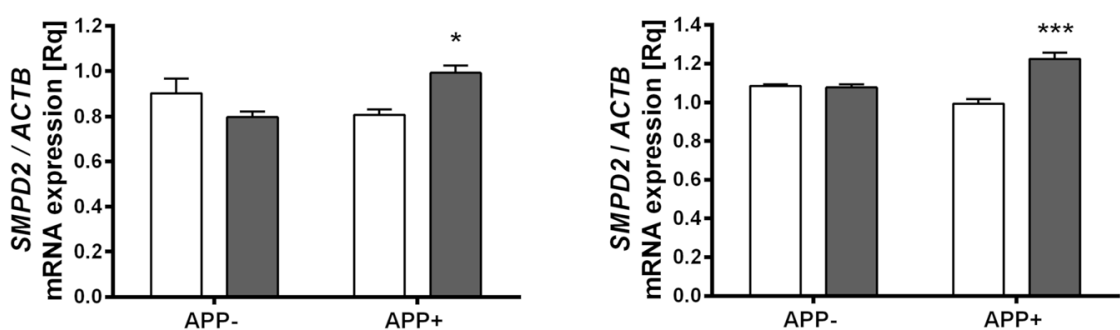

PCR in the hippocampus of $A \beta P P$-transgenic and control mice at the age of 3,6 , and 12 months. $* p<0.05$; ***p $p<0.001$ as compared with the corresponding controls-ANOVA with Tukey post hoc test 
a relative signal strength

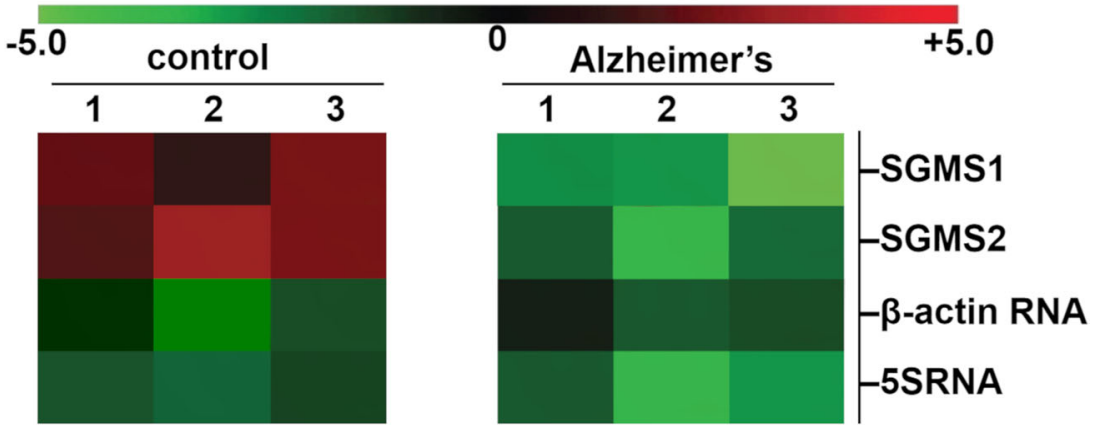

b

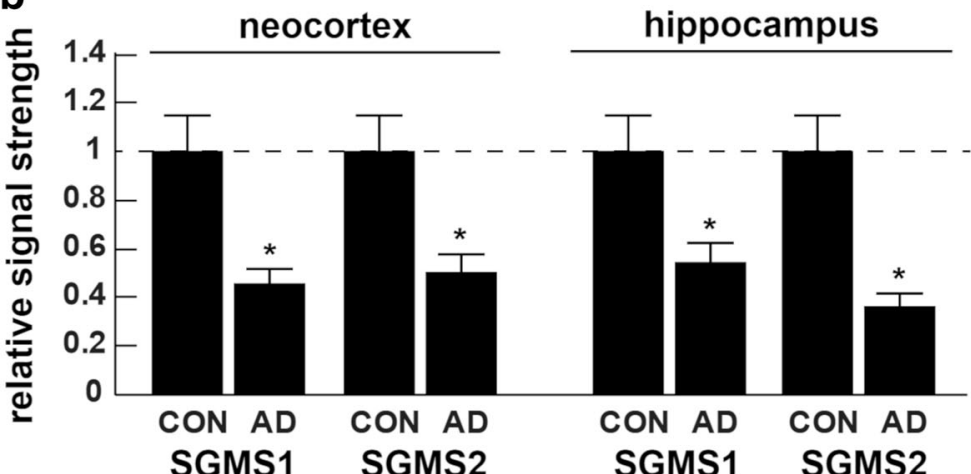

Fig. 6 SGMS1 and SGMS2 mRNA deficits in AD neocortex and hippocampus when compared with age-matched controls. a Brain tissue hippocampal samples $(n=3)$ were analyzed for mRNA abundance from control $(n=3)$ and $\mathrm{AD}$ brains $(n=3)$; control mean age \pm one standard deviation was $70.3 \pm 8.5$ years; and $\mathrm{AD}$ mean age \pm one standard deviation was $71.7 \pm 9.2$ years; there were no significant differences in the age, total RNA yield, post-mortem interval (all PMI $\sim 3 \mathrm{~h}$ or less), or total RNA purity between the control and AD samples; the control markers $\beta$-actin and 5S RNA showed no difference in abundance

between control and AD; however, in the hippocampus, SGMS1 and SGMS2 were reduced to 0.54 and 0.36 of age-matched neurologically normal control values, respectively. b Data in bar graph format for the levels of SGMS1 and SGMS2 mRNA in AD neocortex and hippocampus; a dashed horizontal line at 1.0 is included for ease of comparison and represents control signals in each of the 4 determinations; for both neocortex and hippocampus $(n=3) ; * p<0.05$ (ANOVA)

However, the changes seem to occur at an early age, long before the disease symptoms fully develop in the model. It corresponds to a degree with the clinical data suggesting early, pre-MCI spike of ceramide production [7]. It has recently been proposed that hippocampal changes in ceramide synthases could also be involved in alterations of oxidative stress, mitochondrial respiration, energy and fatty acid metabolism, transcriptional regulation, and DNA repair [reviewed in 67-70]. Ceramides and other sphingolipids are known to influence activities of transcriptional regulators including p53, AP-1, NF- $\mathrm{kB}$, signal transducer and activator of transcription 3 (STAT3), or the splicing regulator serine/arginine-rich splicing-factor 1 (SRSF1) [71-73; reviewed in 14 and 67]. Sphingolipid metabolism is also implicated in DNA damage response regulating proteins such as poly(ADPribose) polymerase, $\mathrm{p} 21, \mathrm{p} 53$, or retinoblastoma $(\mathrm{Rb})$ [reviewed in 74 and 75 ].

Fingolimod is a clinically available modulator of S1PRdependent signaling events, including gene transcription. Strikingly, its effects on A $\beta$ PP-expressing brains appear different from those on control tissue, suggesting that it might interact with the mechanisms of $A \beta / A \beta P P$ impact. Reduced

mRNA for S1PRI and upregulated SIPR3 we previously observed in AD brains might lead to changes in the G proteinmediated regulation of genes engaged in sphingolipid metabolism and signaling [10,11, 27]), Thus, altered S1PR1 may change fingolimod's effects in the Alzheimer's brain. Indeed, in the current work, we have observed widespread modification of the gene expression pattern in fingolimod-treated $\mathrm{APP}^{+}$ mice in an age-dependent manner (Fig. 7). SPHKs and CERKs responded positively to the treatment of 12 -month-old $\mathrm{APP}^{+}$ animals [27]. However, our current results demonstrate a shift in the reaction of sphingolipid metabolism to fingolimod administration in the hippocampus, occurring between 6 and 12 months of age. Importantly, at 3 months, FTY720 reduced the mRNAs for ceramide synthase 2 , potentially blunting the already accumulating pro-apoptotic stimulus. A similar trend appeared to affect CERS4 and CERS6, although without reaching significance. At 6 months, fingolimod in turn upregulated ceramidase $A S A H 1$ and increased both enzymes of the ceramide - sphingomyelin metabolism (SGMS2, SMPD2), which may have impact not only on ceramide but also on other signaling pathways (such as diacylglycerol- or lipid raft- 
Fig. 7 The influence of fingolimod (FTY720) on A $\beta-/$ A $\beta$ PP-altered sphingolipid metabolic enzymes. Female FVBTg(Thy1; APP LD2/B6) mice expressing human $\mathrm{A} \beta \mathrm{PP}$ with the "London" V717I mutation display altered expression of sphingosine kinase $S P H K 2$, ceramide kinase (CERK), and sphingomyelin synthases (SGMS1, SGMS2) in an agedependent manner (different sets of changes at 3,6 , and 12 months of age ([27] and current results). Treatment of $\mathrm{A} \beta \mathrm{PP}$-transgenic animals with FTY720 reverses these changes (in addition to triggering further alterations in mRNAs which do not respond to $\mathrm{A} \beta / \mathrm{A} \beta \mathrm{PP}$ —omitted for clarity)

\section{V717I AßPP}

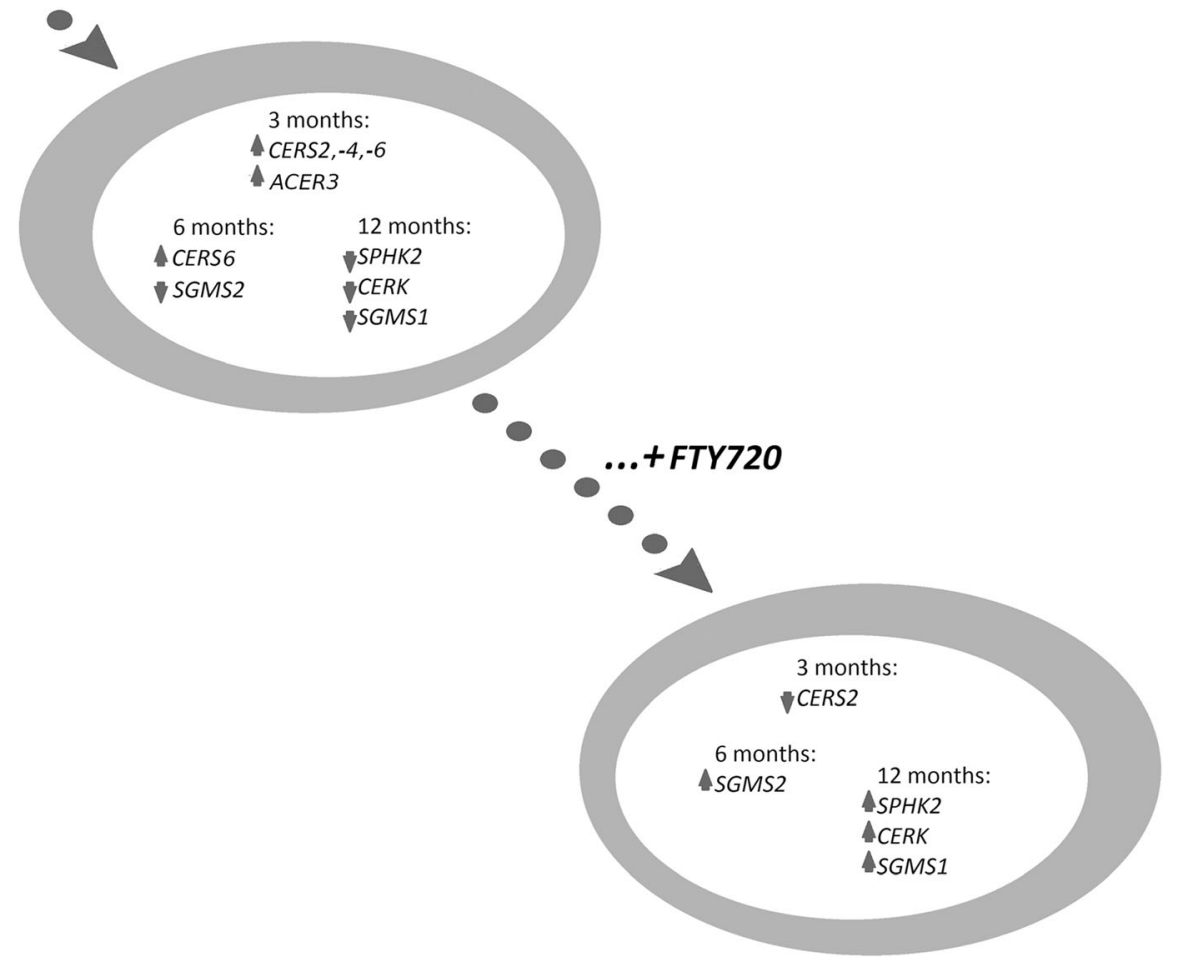

dependent ones). At 12 months, the compound increased $S G M S 1$, which was reduced in the A $\beta$ PP-transgenic animals, and also increased several genes (CERS4, ACER3, ASAH1, and SMPD2), which remained at the same levels in transgenic and transgene-lacking control animals. The corresponding proteins take part in both the production (CERS4, SMPD2) and the utilization of ceramide (ACER3, ASAH1). These effects may be highly important aspects of the proposed neuroprotective activity of fingolimod in $\mathrm{AD}$, suggesting its influence in the very early stages of the neurodegenerative processes (Fig. 7) in addition to the previously published restoration of $B C L 2$ expression at later stages. Our results also confirm the reduction in the brain-enriched sphingomyelin synthases $S G M S 1$ and SGMS2 also in human AD neocortex and hippocampus (Fig. 6), suggesting a deficiency in the capability to synthesize sufficient amounts of sphingomyelin in anatomical regions of the brain targeted by the $\mathrm{AD}$ process.

Thus far, fingolimod's effects on AD and its models were largely analyzed from the perspective of the established immunomodulatory function of sphingolipid signaling [76]. $A \beta$ is considered to trigger immune activation of glial cells, which attempt to remove it from extracellular space, but can accelerate the damage to neighboring neurons as a side effect. Fingolimod has been shown to reduce inflammatory markers in CA1/subiculum and the numbers of activated microglial cells in the hippocampus in the $5 \times \mathrm{FAD}$ mouse model. In the same time, fingolimod reduced $A \beta_{42}$ plaque density and the total level of $A \beta_{42}$ [77]. The mechanism of $A \beta$ accumulation may be augmented by proinflammatory environment in the diseased brain, which is suggested to impair $A \beta$ clearance by astrocytes [78]. Mice overexpressing $A \beta P P$ and presenilin 1 display activated local astroglia and microglia, infiltration of peripheral macrophages and natural killer cells [79]. Infections, susceptibility to which rises in old age, are noted to accelerate the cognitive deterioration of $A D$ patients [80] and to increase $A \beta$ burden in animal models [78]. FTY720 has been shown to inhibit the infection-related activation of astrocytes, and to prevent accumulation of soluble and plaque $A \beta$ in the mouse brain probably through stimulation of $A \beta$ phagocytosis [78]. Fingolimod also restores neurotrophin production and blocks neuronal death occurring in response to $A \beta$ $[34,81]$. These effects lead to improved associative learning and object recognition in mice receiving stereotactic injections of oligomeric A $\beta$ [81]. FTY720 has also been tested in models of other neurodegenerative disorders and provided Akt-mediated neuroprotection in a mouse model of Parkinson's disease [82]. These results only show some aspects of the usefulness of fingolimod as a research tool and potential treatment in neurodegeneration. However, the wide spectrum of interactions of genetic background, age, and environmental factors with sphingolipids, signaling pathways such as PI3K-Akt, A $\beta / \mathrm{A} \beta \mathrm{PP}$ metabolism, and transcription factors/histone deacetylases pose a great challenge in pharmacotherapy. The increasing complexity 
of sphingolipid-based modulation of neuronal phenotype and survival in the diseased brain and its reactions to treatment [27] urges for further elucidation of the multiple effects of fingolimod/FTY720 in Alzheimer's disease.

\section{Concluding Remarks}

Our result confirms that the presence of disease-associated (V717I-mutated) A $\beta$ precursor protein leads to early changes in the expression of sphingolipid-related genes, mainly those engaged in ceramide biosynthesis. During the process of aging, the pattern of hippocampal expression evolves in likely interaction with the ongoing pathological changes. Enhanced expression of ceramide synthases and ceramidase starting from 3 months of age suggests intensification of sphingolipid metabolism in early stages of the disease. Increased ceramide synthase persisted into the age of 6 months; at the same age, reduction of sphingomyelin synthase appeared in $\mathrm{APP}^{+}$hippocampus (SGMS2) and the trend continued into the age of 12 months (SGMS1). Thus, at 6 and 12 months, the A $\beta$ PPinduced changes in gene regulation may lead to the observed imbalance between ceramide and S1P (sphingosine-1-phosphate) in the direction of ceramide signaling, triggering crucial deregulation in survival/death equilibrium.

Sphingosine-1-phosphate receptor modulator FTY720 (fingolimod) counters the observed $\mathrm{A} \beta \mathrm{\beta}-\mathrm{A} \beta \mathrm{PP}$-evoked disturbances in a spatiotemporally specific fashion, showing its potential to alter the disease course. We have previously confirmed apparent pro-survival reaction to fingolimod in the hippocampus of 12-month-old AD model mice that involved sphingosine kinase, ceramide kinase, and BCL2 [27]. However, our current results suggest much more complex image (Fig. 7). While the changes at 3 months seem to favor reduction of ceramide levels, at 12 months, fingolimod accelerated metabolic turnover of ceramide also in the sphingomyelinase pathway and induced further alterations unrelated to the effects of $A \beta P P$. These novel findings prompt for both caution and hope in the consideration of fingolimod as a candidate repurposed drug for the treatment of $\mathrm{AD}$ and other neurodegenerative disorders. Further extensive examination of fingolimod's effects is necessary.

Funding Information The work was supported by the National Science Centre (PL) grant no. NCN 2014/15/B/NZ3/01049 (Figs. 1, 2, 3, 4, 5, 7). Research on human brain (Fig. 6) was supported through an unrestricted grant to the LSU Eye Center from Research to Prevent Blindness (RPB), the Louisiana Biotechnology Research Network (LBRN), and NIH grants NEI EY006311, NIA AG18031, and NIA AG038834 (WJL).

\section{Compliance with Ethical Standards}

All experiments were approved by the IV Local Ethics Committee for Animal Experimentation in Warsaw and performed in accordance with guidelines of the EU Directive 2010/63/EU and with the ARRIVE guidelines. Brain tissues were used in accordance with the institutional review board/ethical guidelines at the Louisiana State University Health Sciences Center and donor institutions.

Conflict of Interest The authors declare that they have no conflict of interest.

Disclaimer The granting institution had no role in data collection, analysis, or interpretation, in the manuscript preparation, or in the decision to submit it for publication. The content of this manuscript is solely the responsibility of the authors and does not necessarily represent the official views of the National Institute on Aging, the National Center for Research Resources, or the National Institutes of Health.

Open Access This article is licensed under a Creative Commons Attribution 4.0 International License, which permits use, sharing, adaptation, distribution and reproduction in any medium or format, as long as you give appropriate credit to the original author(s) and the source, provide a link to the Creative Commons licence, and indicate if changes were made. The images or other third party material in this article are included in the article's Creative Commons licence, unless indicated otherwise in a credit line to the material. If material is not included in the article's Creative Commons licence and your intended use is not permitted by statutory regulation or exceeds the permitted use, you will need to obtain permission directly from the copyright holder. To view a copy of this licence, visit http://creativecommons.org/licenses/by/4.0/.

\section{References}

1. Winblad B, Amouyel P, Andrieu S, Ballard C, Brayne C, Brodaty H et al (2016) Defeating Alzheimer's disease and other dementias: a priority for European science and society. The Lancet Neurol 15: 455-532. https://doi.org/10.1016/S1474-4422(16)00062-4

2. Brunkhorst R, Vutukuri R, Pfeilschifter W (2014) Fingolimod for the treatment of neurological diseases-state of play and future perspectives. Front Cell Neurosci 8:283. https://doi.org/10.3389/fncel. 2014.00283

3. Zhang G, Xie Y, Wang W, Feng X, Jia J (2017) Clinical characterization of an APP mutation (V717I) in five Han Chinese families with early-onset Alzheimer's disease. J Neurol Sci 372:379-386. https://doi.org/10.1016/j.jns.2016.10.039

4. Muratore CR, Rice HC, Srikanth P, Callahan DG, Shin T, Benjamin LNP, Walsh DM, Selkoe DJ et al (2014) The familial Alzheimer's disease APPV717I mutation alters APP processing and tau expression in iPSC-derived neurons. Hum Mol Genet 23:3523-3536. https://doi.org/10.1093/hmg/ddu064

5. Couttas TA, Kain N, Tran C, Chatterton Z, Kwok JB, Don AS (2018) Age-dependent changes to sphingolipid balance in the human hippocampus are gender-specific and may sensitize to neurodegeneration. J Alzheimers Dis 63:503-514. https://doi.org/10. 3233/JAD-171054

6. Couttas TA, Kain N, Daniels B, Lim XY, Shepherd C, Kril J, Pickford R, Li H et al (2014) Loss of the neuroprotective factor sphingosine 1-phosphate early in Alzheimer's disease pathogenesis. Acta Neuropathol Commun 2:9. https://doi.org/10.1186/20515960-2-9

7. Han X (2010) Multi-dimensional mass spectrometry-based shotgun lipidomics and the altered lipids at the mild cognitive impairment stage of Alzheimer's disease. Biochim Biophys Acta 1801:774 783. https://doi.org/10.1016/j.bbalip.2010.01.010 
8. Katsel P, Li C, Haroutunian V (2007) Gene expression alterations in the sphingolipid metabolism pathways during progression of dementia and Alzheimer's disease: a shift toward ceramide accumulation at the earliest recognizable stages of Alzheimer's disease? Neurochem Res 32:845-856. https://doi.org/10.1007/s11064-0079297-x

9. Van Brocklyn JR, Williams JB (2012) The control of the balance between ceramide and sphingosine-1-phosphate by sphingosine kinase: oxidative stress and the seesaw of cell survival and death. Comp Biochem Physiol B: Biochem Mol Biol 163:26-36. https:// doi.org/10.1016/j.cbpb.2012.05.006

10. Huang K, Huang J, Chen C, Hao J, Wang S, Huang J, Liu P, Huang H (2014) AP-1 regulates sphingosine kinase 1 expression in a positive feedback manner in glomerular mesangial cells exposed to high glucose. Cell Signal 26:629-638. https://doi.org/10.1016/j. cellsig.2013.12.002

11. Wegner M-S, Wanger RA, Oertel S, Brachtendorf S, Hartmann D, Schiffmann S, Marschalek R, Schreiber Y et al (2014) Ceramide synthases CerS4 and CerS5 are upregulated by $17 \beta$-estradiol and GPER1 via AP-1 in human breast cancer cells. Biochem Pharmacol 92:577-589. https://doi.org/10.1016/j.bcp.2014.10.007

12. Mullonkal CJ, Toledo-Pereyra LH (2007) Akt in ischemia and reperfusion. J Investig Surg 20:195-203. https://doi.org/10.1080/ 08941930701366471

13. Kaneider NC, Lindner J, Feistritzer C, Sturn DH, Mosheimer BA, Djanani AM, Wiedermann CJ (2004) The immune modulator FTY720 targets sphingosine-kinase-dependent migration of human monocytes in response to amyloid beta-protein and its precursor. FASEB J 18:1309-1311. https://doi.org/10.1096/fj.03-1050fje

14. Jęśko H, Stępień A, Lukiw WJ, Strosznajder RP (2018) The crosstalk between sphingolipids and insulin-like growth factor signaling: significance for aging and neurodegeneration. Mol Neurobiol 56: 3501-3521. https://doi.org/10.1007/s12035-018-1286-3

15. Bidlingmaier S, Ha K, Lee N-K, Su Y, Liu B (2016) Proteome-wide identification of novel ceramide-binding proteins by yeast surface cDNA display and deep sequencing. Mol Cell Proteomics 15: 1232-1245. https://doi.org/10.1074/mcp.M115.055954

16. Elsen L, Betz R, Schwarzmann G, Sandhoff K, van Echten-Deckert $\mathrm{G}$ (2002) Identification of ceramide binding proteins in neuronal cells: a critical point of view. Neurochem Res 27:717-727. https:// doi.org/10.1023/A:1020288403626

17. Jazvinšćak Jembrek M, Hof PR, Šimić G (2015) Ceramides in Alzheimer's disease: key mediators of neuronal apoptosis induced by oxidative stress and $A \beta$ accumulation. Oxidative Med Cell Longev 2015:346783. https://doi.org/10.1155/2015/346783

18. Krönke M (1999) Biophysics of ceramide signaling: interaction with proteins and phase transition of membranes. Chem Phys Lipids 101:109-121. https://doi.org/10.1016/S0009-3084(99) 00059-6

19. Snook CF, Jones JA, Hannun YA (2006) Sphingolipid-binding proteins. Biochim Biophys Acta 1761:927-946. https://doi.org/10. 1016/j.bbalip.2006.06.004

20. van Blitterswijk WJ, van der Luit AH, Veldman RJ, Verheij M, Borst J (2003) Ceramide: second messenger or modulator of membrane structure and dynamics? Biochem J 369:199-121. https://doi. org/10.1042/BJ20021528

21. Puglielli L, Ellis BC, Saunders AJ, Kovacs DM (2003) Ceramide stabilizes beta-site amyloid precursor protein-cleaving enzyme 1 and promotes amyloid beta-peptide biogenesis. J Biol Chem 278: 19777-19783. https://doi.org/10.1074/jbc.M300466200

22. Sawamura N, Ko M, Yu W, Zou K, Hanada K, Suzuki T et al (2004) Modulation of amyloid precursor protein cleavage by cellular sphingolipids. J Biol Chem 279:11984-11991. https://doi.org/10. 1074/jbc.M309832200

23. Tamboli IY, Prager K, Barth E, Heneka M, Sandhoff K, Walter J (2005) Inhibition of glycosphingolipid biosynthesis reduces secretion of the beta-amyloid precursor protein and amyloid betapeptide. J Biol Chem 280:28110-28117. https://doi.org/10.1074/ jbc.M414525200

24. Varma VR, Oommen AM, Varma S, Casanova R, An Y, Andrews RM, O'Brien R, Pletnikova O et al (2018) Brain and blood metabolite signatures of pathology and progression in Alzheimer disease: a targeted metabolomics study. PLoS Med 15:e1002482. https:// doi.org/10.1371/journal.pmed.1002482

25. Fonteh AN, Ormseth C, Chiang J, Cipolla M, Arakaki X, Harrington MG (2015) Sphingolipid metabolism correlates with cerebrospinal fluid beta amyloid levels in Alzheimer's disease. PLoS One 10:e0125597. https://doi.org/10.1371/journal.pone. 0125597

26. Cavanaugh SE, Pippin JJ, Barnard ND (2014) Animal models of Alzheimer disease: historical pitfalls and a path forward. ALTEX 31:279-302. https://doi.org/10.14573/altex.1310071

27. Jęśko H, Wencel PL, Lukiw WJ, Strosznajder RP (2018) Modulatory effects of fingolimod (FTY720) on the expression of sphingolipid metabolism-related genes in an animal model of Alzheimer's disease. Mol Neurobiol 56:174-185. https://doi.org/ 10.1007/s12035-018-1040-x

28. Caselli RJ, Beach TG, Knopman DS, Graff-Radford NR (2017) Alzheimer disease: scientific breakthroughs and translational challenges. Mayo Clin Proc 92:978-994. https://doi.org/10.1016/j. mayocp.2017.02.011

29. Zhang M, Schmitt-Ulms G, Sato C, Xi Z, Zhang Y, Zhou Y, St George-Hyslop P, Rogaeva E (2016) Drug repositioning for Alzheimer's disease based on systematic "omics" data mining. PLoS One 11:e0168812. https://doi.org/10.1371/journal.pone. 0168812

30. Hunter SF, Bowen JD, Reder AT (2016) The direct effects of fingolimod in the central nervous system: implications for relapsing multiple sclerosis. CNS Drugs 30:135-147. https://doi.org/10. 1007/s40263-015-0297-0

31. Safarian F, Khallaghi B, Ahmadiani A, Dargahi L (2015) Activation of S1P1 receptor regulates $\mathrm{PI} 3 \mathrm{~K} / \mathrm{Akt} / \mathrm{FoxO} 3$ a pathway in response to oxidative stress in PC12 cells. J Mol Neurosci 56: 177-187. https://doi.org/10.1007/s12031-014-0478-1

32. Moloney AM, Griffin RJ, Timmons S, O'Connor R, Ravid R, O'Neill C (2010) Defects in IGF-1 receptor, insulin receptor and IRS-1/2 in Alzheimer's disease indicate possible resistance to IGF1 and insulin signalling. Neurobiol Aging 31:224-243. https://doi. org/10.1016/j.neurobiolaging.2008.04.002

33. Lauzon M-A, Daviau A, Marcos B, Faucheux N (2015) Growth factor treatment to overcome Alzheimer's dysfunctional signaling. Cell Signal 27:1025-1038. https://doi.org/10.1016/j.cellsig.2015. 02.018

34. Ruiz A, Joshi P, Mastrangelo R, Francolini M, Verderio C, Matteoli $M(2014)$ Testing A $\beta$ toxicity on primary CNS cultures using drugscreening microfluidic chips. Lab Chip 14:2860-2866. https://doi. org/10.1039/c4lc00174e

35. Hasegawa Y, Suzuki H, Sozen T, Rolland W, Zhang JH (2010) Activation of sphingosine 1-phosphate receptor-1 by FTY720 is neuroprotective after ischemic stroke in rats. Stroke 41:368-374. https://doi.org/10.1161/STROKEAHA.109.568899

36. Hsu C-K, Lee I-T, Lin C-C et al (2015) Sphingosine-1-phosphate mediates COX-2 expression and PGE2/IL-6 secretion via c-Srcdependent AP-1 activation. J Cell Physiol 230:702-715. https://doi. org/10.1002/jcp. 24795

37. Su D, Cheng Y, Li S, Dai D, Zhang W, Lv M (2017) Sphk1 mediates neuroinflammation and neuronal injury via TRAF2/NF- $\mathrm{BB}$ pathways in activated microglia in cerebral ischemia reperfusion. J Neuroimmunol 305:35-41. https://doi.org/10.1016/j.jneuroim. 2017.01.015

38. Anastasiadou S, Knöll B (2016) The multiple sclerosis drug fingolimod (FTY720) stimulates neuronal gene expression, axonal 
growth and regeneration. Exp Neurol 279:243-260. https://doi.org/ 10.1016/j.expneurol.2016.03.012

39. Hoffmann FS, Hofereiter J, Rübsamen H, Melms J, Schwarz S, Faber H, Weber P, Pütz B et al (2015) Fingolimod induces neuroprotective factors in human astrocytes. J Neuroinflammation 12: 184. https://doi.org/10.1186/s12974-015-0393-6

40. Hait NC, Allegood J, Maceyka M, Strub GM, Harikumar KB, Singh SK, Luo C, Marmorstein R et al (2009) Regulation of histone acetylation in the nucleus by sphingosine-1-phosphate. Science 325(5945):1254-1257. https://doi.org/10.1126/science.1176709

41. Hait NC, Wise LE, Allegood JC, O’Brien M, Avni D, Reeves TM, Knapp PE, Lu J et al (2014) Active, phosphorylated fingolimod inhibits histone deacetylases and facilitates fear extinction memory. Nat Neurosci 17:971-980. https://doi.org/10.1038/nn.3728

42. Hait NC, Avni D, Yamada A, Nagahashi M, Aoyagi T, Aoki H, Dumur CI, Zelenko Z et al (2015) The phosphorylated prodrug FTY720 is a histone deacetylase inhibitor that reactivates ER $\alpha$ expression and enhances hormonal therapy for breast cancer. Oncogenesis. 4:e156. https://doi.org/10.1038/oncsis.2015.16

43. Ji J, Wang J, Yang J, Wang XP, Huang JJ, Xue TF, Sun XL (2019) The intra-nuclear SphK2-S1P Axis facilitates M1-to-M2 shift of microglia via suppressing HDAC1-mediated KLF4 deacetylation. Front Immunol 10:1241. https://doi.org/10.3389/fimmu.2019. 01241 eCollection 2019

44. van Doorn R, Nijland PG, Dekker N, Witte ME, Lopes-Pinheiro MA, van het Hof B, Kooij G, Reijerkerk A et al (2012) Fingolimod attenuates ceramide-induced blood-brain barrier dysfunction in multiple sclerosis by targeting reactive astrocytes. Acta Neuropathol 124:397-410. https://doi.org/10.1007/s00401-012$1014-4$

45. Hashemian M, Ghasemi-Kasman M, Parsian H, Sadeghi F (2019) Fingolimod (FTY720) improves the functional recovery and myelin preservation of the optic pathway in focal demyelination model of rat optic chiasm. Brain Res Bull 153:109-121. https://doi.org/10. 1016/j.brainresbull.2019.08.014

46. Segura-Ulate I, Yang B, Vargas-Medrano J, Perez RG (2017) FTY720 (fingolimod) reverses $\alpha$-synuclein-induced downregulation of brain-derived neurotrophic factor mRNA in OLN-93 oligodendroglial cells. Neuropharmacology 117:149-157. https://oi. org/10.1016/j.neuropharm.2017.01.028

47. Rumah KR, Vartanian TK, Fischetti VA. (2017) Oral multiple sclerosis drugs inhibit the in vitro growth of epsilon toxin producing gut bacterium, Clostridium perfringens. Front Cell Infect Microbiol 7: 11. doi: https://doi.org/10.3389/fcimb.2017.00011.

48. Vidal-Martinez G, Chin B, Camarillo C, Herrera GV, Yang B, Sarosiek I, Perez RG (2019) A pilot microbiota study in Parkinson's disease patients versus control subjects, and effects of FTY720 and FTY720-mitoxy therapies in parkinsonian and multiple system atrophy mouse models. J Park Dis. https://doi.org/10. 3233/JPD-191693

49. Moechars D, Dewachter I, Lorent K, Reversé D, Baekelandt V, Naidu A, Tesseur I, Spittaels K et al (1999) Early phenotypic changes in transgenic mice that overexpress different mutants of amyloid precursor protein in brain. J Biol Chem 274:6483-6492. https://doi. org/10.1074/jbc.274.10.6483

50. Van Dorpe J, Smeijers L, Dewachter I, Nuyens D, Spittaels K, Van Den Haute C et al (2000) Prominent cerebral amyloid angiopathy in transgenic mice overexpressing the London mutant of human APP in neurons. Am J Pathol 157:1283-1298. https://doi.org/10.1016/ S0002-9440(10)64644-5

51. Potenza RL, De Simone R, Armida M, Mazziotti V, Pèzzola A, Popoli P, Minghetti L (2016) Fingolimod: a disease-modifier drug in a mouse model of amyotrophic lateral sclerosis. Neurotherapeutics 13:918-927. https://doi.org/10.1007/s13311016-0462-2
52. Gol M, Ghorbanian D, Hassanzadeh S, Javan M, Mirnajafi-Zadeh J, Ghasemi-Kasman M (2017) Fingolimod enhances myelin repair of hippocampus in pentylenetetrazol-induced kindling model. Eur J Pharm Sci 96:72-83. https://doi.org/10.1016/j.ejps.2016.09.016

53. Becker-Krail D, Farrand AQ, Boger HA, Lavin A (2017) Effects of fingolimod administration in a genetic model of cognitive deficits. J Neurosci Res 95:1174-1181. https://doi.org/10.1002/jnr.23799

54. Colangelo V, Schurr J, Ball MJ, Pelaez RP, Bazan NG, Lukiw WJ (2002) Gene expression profiling of 12633 genes in Alzheimer hippocampal CA1: transcription and neurotrophic factor downregulation and up-regulation of apoptotic and pro-inflammatory signaling. J Neurosci Res 70:462-473

55. Lukiw WJ (2004) Gene expression profiling in fetal, aged, and Alzheimer hippocampus: a continuum of stress-related signaling. Neurochem Res 29:1287-1297

56. Cui JG, Hill JM, Zhao Y, Lukiw WJ (2007) Expression of inflammatory genes in the primary visual cortex of late-stage Alzheimer's disease. Neuroreport. 18:115-119

57. Cui JG, Zhao Y, Lukiw WJ (2005) Isolation of high spectral quality RNA using run-on gene transcription; application to gene expression profiling of human brain. Cell Mol Neurobiol 25:789-794

58. Lukiw WJ, LeBlanc HJ, Carver LA, McLachlan DR, Bazan NG (1998) Run-on gene transcription in human neocortical nuclei. Inhibition by nanomolar aluminum and implications for neurodegenerative disease. J Mol Neurosci 11:67-78

59. Lukiw WJ, Bazan NG (2010) Inflammatory, apoptotic, and survival gene signaling in Alzheimer's disease. A review on the bioactivity of neuroprotectin D1 and apoptosis. Mol Neurobiol 42:10-16. https://doi.org/10.1007/s12035-010-8126-4

60. Pogue AI, Dua P, Hill JM, Lukiw WJ (2015) Progressive inflammatory pathology in the retina of aluminum-fed $5 \mathrm{xFAD}$ transgenic mice. J Inorg Biochem 152:206-209. https://doi.org/10.1016/j. jinorgbio.2015.07.009

61. Cui JG, Li YY, Zhao Y, Bhattacharjee S, Lukiw WJ (2010) Differential regulation of interleukin-1 receptor-associated kinase1 (IRAK-1) and IRAK-2 by microRNA-146a and NF-kappaB in stressed human astroglial cells and in Alzheimer disease. J Biol Chem 285(50):38951-38960. https://doi.org/10.1074/jbc.M110. 178848

62. Lukiw WJ (2012) NF-кB-regulated micro RNAs (miRNAs) in primary human brain cells. Exp Neurol 235:484-490. https://doi.org/ 10.1016/j.expneurol.2011.11.022

63. Bilal F, Montfort A, Gilhodes J, Garcia V, Riond J, Carpentier S, Filleron T, Colacios C et al (2019) Sphingomyelin synthase 1 (SMS1) downregulation is associated with sphingolipid reprogramming and a worse prognosis in melanoma. Front Pharm 10:443. https://doi.org/10.3389/fphar.2019.00443

64. Zhang P, Hua L, Hou H, Du X, He Z, Liu M, Hu X, Yan N (2018) Sphingomyelin synthase 2 promotes $\mathrm{H} 2 \mathrm{O} 2$-induced endothelial dysfunction by activating the $\mathrm{Wnt} / \beta$-catenin signaling pathway. Int J Mol Med 42:3344-3354. https://doi.org/10.3892/ijmm.2018. 3888

65. Hagen N, Hans M, Hartmann D, Swandulla D, van Echten-Deckert G (2011) Sphingosine-1-phosphate links glycosphingolipid metabolism to neurodegeneration via a calpain-mediated mechanism. Cell Death Differ 18:1356-1365. https://doi.org/10.1038/cdd.2011.7

66. Rivera I-G, Ordoñez M, Presa N, Gomez-Larrauri A, Simón J, Trueba M, Gomez-Muñoz A (2015) Sphingomyelinase $\mathrm{D} /$ ceramide 1-phosphate in cell survival and inflammation. Toxins (Basel) 7:1457-1466. https://doi.org/10.3390/toxins7051457

67. Czubowicz K, Jęśko H, Wencel P, Lukiw WJ, Strosznajder RP (2019) The role of ceramide and sphingosine-1-phosphate in Alzheimer's disease and other neurodegenerative disorders. Mol Neurobiol 56:5436-5455. https://doi.org/10.1007/s12035-018$1448-3$ 
68. Kogot-Levin A, Saada A (2014) Ceramide and the mitochondrial respiratory chain. Biochimie 100:88-94. https://doi.org/10.1016/j. biochi.2013.07.027

69. Turner N, Lim XY, Toop HD, Osborne B, Brandon AE, Taylor EN, Fiveash CE, Govindaraju $\mathrm{H}$ et al (2018) A selective inhibitor of ceramide synthase 1 reveals a novel role in fat metabolism. Nat Commun 9:3165. https://doi.org/10.1038/s41467-018-05613-7

70. Zigdon H, Kogot-Levin A, Park JW, Goldschmidt R, Kelly S, Merrill AH Jr, Scherz A, Pewzner-Jung Y et al (2013) Ablation of ceramide synthase 2 causes chronic oxidative stress due to disruption of the mitochondrial respiratory chain. J Biol Chem 288:49474956. https://doi.org/10.1074/jbc.M112.402719

71. Lu S, Natarajan SK, Mott JL, Kharbanda KK, Harrison-Findik DD (2016) Ceramide induces human hepcidin gene transcription through JAK/STAT3 pathway. PLoS One 11:e0147474. https:// doi.org/10.1371/journal.pone.0147474

72. Patwardhan GA, Hosain SB, Liu DX, Khiste SK, Zhao Y, Bielawski J, Jazwinski SM, Liu YY (2014) Ceramide modulates pre-mRNA splicing to restore the expression of wild-type tumor suppressor p53 in deletion-mutant cancer cells. Biochim Biophys Acta 1841:1571-1580. https://doi.org/10.1016/j.bbalip.2014.08. 017

73. Sociale M, Wulf AL, Breiden B, Klee K, Thielisch M, Eckardt F, Sellin J, Bülow MH et al (2018) Ceramide synthase Schlank is a transcriptional regulator adapting gene expression to energy requirements. Cell Rep 22:967-978. https://doi.org/10.1016/j.celrep. 2017.12.090

74. Carroll B, Donaldson JC, Obeid L (2015) Sphingolipids in the DNA damage response. Adv Biol Regul 58:38-52. https://doi. org/10.1016/j.jbior.2014.11.001

75. Jeffries KA, Krupenko NI (2018) Ceramide signaling and p53 pathways. Adv Cancer Res 140:191-215. https://doi.org/10.1016/bs. acr.2018.04.011

76. Hemmati F, Dargahi L, Nasoohi S, Omidbakhsh R, Mohamed Z, Chik Z, Naidu M, Ahmadiani A (2013) Neurorestorative effect of
FTY720 in a rat model of Alzheimer's disease: comparison with memantine. Behav Brain Res 252:415-421. https://doi.org/10. 1016/j.bbr.2013.06.016

77. Aytan N, Choi J-K, Carreras I, Brinkmann V, Kowall NW, Jenkins BG, Dedeoglu A (2016) Fingolimod modulates multiple neuroinflammatory markers in a mouse model of Alzheimer's disease. Sci Rep 6:24939. https://doi.org/10.1038/srep24939

78. McManus RM, Finucane OM, Wilk MM, Mills KHG, Lynch MA (2017) FTY720 attenuates infection-induced enhancement of A $\beta$ accumulation in APP/PS1 mice by modulating astrocytic activation. J NeuroImmune Pharmacol 12:670-681. https://doi.org/10. 1007/s11481-017-9753-6

79. Kelly RJ, Minogue AM, Lyons A, Jones RS, Browne TC, Costello DA, Denieffe S, O'Sullivan C et al (2013) Glial activation in $\mathrm{A} \beta \mathrm{PP} / \mathrm{PS} 1$ mice is associated with infiltration of IFN $\gamma$-producing cells. J Alzheimers Dis 37:63-75. https://doi.org/10.3233/JAD130539

80. Holmes C, Cunningham C, Zotova E, Woolford J, Dean C, Kerr S, Culliford D, Perry VH (2009) Systemic inflammation and disease progression in Alzheimer disease. Neurology. 73:768-774. https:// doi.org/10.1212/WNL.0b013e3181b6bb95

81. Fukumoto K, Mizoguchi H, Takeuchi H, Horiuchi H, Kawanokuchi J, Jin S et al (2014) Fingolimod increases brain-derived neurotrophic factor levels and ameliorates amyloid $\beta$-induced memory impairment. Behav Brain Res 268:88-93. https://doi.org/10.1016/j.bbr. 2014.03.046

82. Motyl J, Przykaza Ł, Boguszewski PM, Kosson P, Strosznajder JB (2018) Pramipexole and fingolimod exert neuroprotection in a mouse model of Parkinson's disease by activation of sphingosine kinase 1 and Akt kinase. Neuropharmacology 135:139-150. https:// doi.org/10.1016/j.neuropharm.2018.02.023

Publisher's Note Springer Nature remains neutral with regard to jurisdictional claims in published maps and institutional affiliations. 